\title{
OSTEOCHONDRITIS DISSECANS OF THE TALUS IN IDENTICAL TWINS
}

\author{
KEVIN WOODS, IAN HARRIS
}

Osteochondritis dissecans (OCD) is of uncertain aetiology, although trauma, ischaemia, accessory centres of ossification and genetic factors have been proposed. It sometimes affects the dome of the talus; we describe identical lesions in identical twins. reports of a familial incidence. Autosomal dominant inheritance has been described, sometimes associated with short stature, and generally involving the knee or ankle (Petrie 1977).

OCD of the talus has been reported to have a high

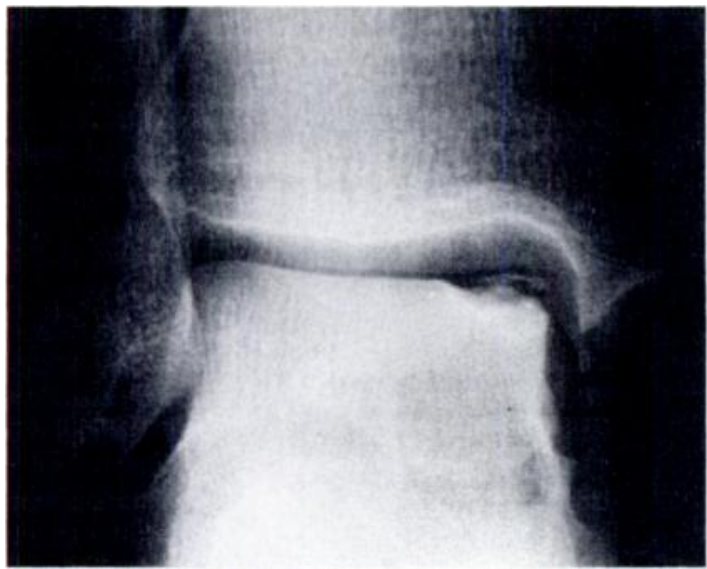

Fig. 1

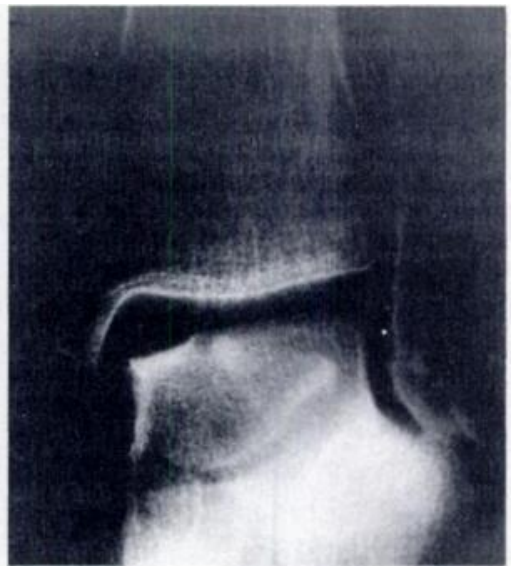

Fig. 2
Case reports. Identical female twins aged 21 years presented two months apart to the same orthopaedic surgeon with recurrent pain in their right ankles, exacerbated by exercise. Onset had been gradual and was not related to trauma. Both patients had tenderness over the anteromedial aspect of the talar dome with no evidence of instability or ligamentous laxity. There were no other siblings and no family history of OCD or endocrine diseases. Radiographs showed lesions of the medial talar dome in both patients (Figs 1 and 2), and the finding was confirmed arthroscopically.

Discussion. Trauma and ischaemia are popular theories for the cause of osteochondritis dissecans but there are many

K. Woods, FRACS, Orthopaedic Surgeon

I. Harris, MB BS, Orthopaedic Registrar

Woden Valley Hospital, Woden, A.C.T.

Correspondence to Dr. I. Harris at 30 Percival Road, Caringbah, New South Wales 2229, Australia.

C1995 British Editorial Society of Bone and Joint Surgery

0301-620X/95/2R34 \$2.00

J Bone Joint Surg [Br] 1995;77-B:331.

Received 2 June 1994; Accepted 8 July 1994 incidence of associated trauma (Roden, Tillegard and Onander-Scharin 1953; Canale and Belding 1980; Flick and Gould 1985). Nearly all lesions involving the lateral talar dome were linked with trauma, but this was implicated in a significantly smaller proportion of the medial lesions.

The finding of almost identical medial talar lesions in identical twins suggests an underlying predisposition to this condition, presumably of an inherited nature, and therefore supports the theory of genetic predisposition in the aetiology of osteochondritis dissecans.

No benefits in any form have been received or will be received from a commercial party related directly or indirectly to the subject of this article.

\section{REFERENCES}

Canale ST, Belding RH. Osteochondral lesions of the talus. $J$ Bone Joint Surg [Am] 1980;62-A:97-I02.

Flick AB, Gould N. Osteochondritis dissecans of the talus (transchondra fractures of the talus): review of the literature and new surgical approach for medial dome lesions. Foot Ankle 1985:5:165-85.

Petrie PWR. Aetiology of osteochondritis dissecans: failure to establish a familial background. J Bone Joint Surg /Br/ 1977:59-B:366-7.

Roden S, Tillegard P, Unander-Scharin L. Osteochondritis dissecans and similar lesions of the talus. Acta Orthop Scand 1953:23:51-66. 